\title{
A Crucial Interaction of p62 and Nrf2 in Mediating Metastasis of Esophageal Squamous Cell Cancer
}

\section{Xiuying Chen}

Hubei University of Medicine

Li Yu

Hubei University of Medicine

Junyang Zhou

Hubei University of Medicine

Ji Ren

Guizhou Medical University

\section{Shan Wang}

Hubei University of Medicine

\section{Yujie Tan}

The Affiliated Hospital of Guizhou Medical University

Yan Ding ( 2 20090990@hbmu.edu.cn )

Hubei University of Medicine

\section{Research Article}

Keywords: Sequestosome 1, nuclear factor erythroid 2-related factor 2, Esophageal squamous cell carcinoma, Autophagy, EMT, Metastasis

Posted Date: October 25th, 2021

DOI: https://doi.org/10.21203/rs.3.rs-937268/v1

License: (c) (1) This work is licensed under a Creative Commons Attribution 4.0 International License.

Read Full License 


\section{Abstract}

Background: Sequestosome 1 (SQSTM1), also referred to as p62 and nuclear factor erythroid 2-related factor 2 (Nrf2) have implicated into the pathogenesis of esophageal squamous cell carcinoma (ESCC). While p62 and Nrf2 interact and influence each other in diverse pathological settings, in whether such interaction contributes to ESCC remains unclear. In this study, we aimed to explore the functional significance of p62 and Nrf2 in ESCC, and uncover a interaction between p62 and Nrf2 in mediating ESCC.

Results: Herein, we show a critican interaction betwwen p62 and Nrf2 in ESCC. Huamn GEPIA database analysis revealed the expression of p62 and Nrf2 is upregulated in ESCC, which is further verified by biochemical assessements using a human tumor tissue bank. Genetic knockdown of p62 and/or Nrf2 demonstrated a mediator role of p62 and Nrf2 in the proliferation, migration and movement ability of ECSS cells. In addition, the downregulation of p62 or Nrf2 could change the morphology of ESCC cells, transforming them from shuttle to round shape, and inhibit their EMT. The knockdown approach also reveal a synergy between p62 and Nrf2 in promoting EMT and the invasive growth of ESCC cells. The xenograft assay in vivo revealed similar effects of p62 and/or Nrf2 knockdown on tumorigenesis and metastaisis of ESCC.

Conclusions: These results indicate that p62 and Nrf2 promote EMT and metastasis of ESCC in a synergistic manner. Simultaneously targeting of p62 and Nrf2 may have a therapeutic potential in treating ESCC.

\section{Highlights}

- The expression level of p62 in ESCC tissues was increased

- P62 or Nrf2 can regulate ESCC cell metastasis and F-actin polarization

- P62 or Nrf2 knockdown inhibited ESCC cell EMT

- Simultaneous knockdown of p62 and Nrf2 had the best inhibitory effect on metastasis

\section{Background}

Esophageal carcinoma is the sixth leading cause of cancer deaths in the world. The etiologies are complex and unclear. depending on histological type and population (1). Esophageal carcinoma can be subdivided into adenocarcinoma (AC) and squamous cell carcinoma (SCC) according to histological characteristics(2). The molecular mechanisms underlying esophageal carcinoma remain poorly understood, and the effective therapies are limited. The five-year survival rate for esophageal carcinoma is only about $20 \%$ due to a combination of both local invasion and distant metastasis (3). Many patients 
with esophageal carcinoma have metastasized at the time of diagnosis (4). Therefore, there is an urgent need to develop new therapeutic strategies to combat the cancer metastasis and progression.

Epithelial mesenchymal transion (EMT) is a process by which epithelial cells become mesenchymal stem cells, which is characterized by increased cell protursions, motility and extracellular matrix (ECM) degradation, as well as resistant to senescence and apoptosis $(5,6)$. While EMT has been shown to play an important role in the occurrence and development of cancer, the underlying molecular mechanisms remain incompletely understood(7).

p62, also named Sequestosome 1 (SQSTM1), a multifunctional ubiquitin-binding adaptor protein, has been implicated in many cancers, such as breast cancer (8), liver cancer (9), and gastrointestinal carcinomas (10). At the molecular level, p62 facilitates cancer development and metastasis partly via controlling the stability and activity of multiple EMT factors (11). Nevertheless, whether p62 regulates EMT in esophageal squamous cell carcinoma (ESCC) remains to be determined. On the other hand, nuclear factor erythroid 2-related factor 2 (Nrf2) has been demonstrated to promote the metastasis of esophageal carcinoma in hypoxic microenvironment (12). Of note, p62 is a target gene of Nrf2 and p62 can also upregulate Nrf2 by interfering with Kelch-like ECH associated protein 1 (KEAP1)-mediated Nrf2 degradation, thereby forming a positive feedback loop to intensify p62 expression (13-15). In ESCC, the relationship between $\mathrm{p} 62$ and Nrf2, whether they can regulate ESCC under baseline conditions, and whose regulation is more obvious are still unclear. These findings indicate the potential roles of p62 and Nrf2 as well as their interaction in ESCC.

The present study aimed to investigate he functional significance of p62 and Nrf2 in ESCC, and uncover a interaction between p62 and Nrf2 in mediating ESCC. Both clinical tissues or ESCC cell lines were used to explore the potential of p62 and Nrf2 as biomarkers of ESCC. Knockdown of p62 and Nrf2 were induced through the transfection of knockdown plasmid, to explor the role of p62 and Nrf2 regulating ESCC proliferation and metastasis in vitro and in vivo.These findings indicate a critical interaction between p62 and Nrf2 in mediating ESCC.

\section{Results}

\section{p62 expression is upregulated in ESCC}

To investigate whether p62 is related to the progression of ESCC, we analyzed the expression profile of p62 in various human tumors using the GEPIA database (http://gepia2.cancer-pku.cn/\#index). We found that p62 expression was higher in esophageal carcinoma (ESCA, $n=180)$ compared with the matched normal tissues ( $n=286$ ) (Fig. 1A). Immunohistochemistry and tissue microarray were used to detect the expression of p62 in human ESCC with various differentiation grades $(n=34)$ (Fig. 1B). As shown in Table 1, p62 expression was positively correlated with the degree of ESCC (Fisher's exact test, $\mathrm{P}=0.008$ ) and negatively correlated with it's differentiation degree (Fisher's exact test, $P=0.009)$ (Fig. 1C and Table 2), independent of the age, gender, TNM stage, or position. In highly differentiated ESCC, p62 expression was 
low and mainly localized in the nuclei of basal cells. While in the less differentiated ESCC, p62 expression was relatively high and mainly concentrated in the cytoplasm of the tumor cells (Fig. 1C, 1D, and 1E; $\mathrm{P}=0.001)$. These results demonstrate that the expression of $\mathrm{p} 62$ is upregulated in human ESCC.

Table 1

Correlations between p62 expression and clinicopathologic features in 34 ESCC patients.

\section{Clinicopathological feature}

p62 expression

\begin{tabular}{|c|c|c|c|c|}
\hline & Total & Low & High & \\
\hline & 34 & $\mathrm{n}=12$ & $\mathrm{n}=22$ & \\
\hline & & $(35.3 \%)$ & $(64.7 \%)$ & \\
\hline \multicolumn{5}{|l|}{ Age (years) } \\
\hline$<65$ & 24 & $8(66.7)$ & $16(72.7)$ & 0.714 \\
\hline$\geq 65$ & 10 & $4(33.3)$ & $6(27.3)$ & \\
\hline \multicolumn{5}{|l|}{ Gender } \\
\hline Male & 26 & $9(75.0)$ & 17(77.3) & 1 \\
\hline Female & 8 & $3(25.0)$ & $5(22.7)$ & \\
\hline \multicolumn{5}{|c|}{ TNM stage(AJCC) } \\
\hline Stage I-II & 22 & $7(58.3)$ & $15(68.2)$ & 0.711 \\
\hline Stage III-IV & 12 & $5(41.7)$ & $7(31.8)$ & \\
\hline \multicolumn{5}{|l|}{ Position } \\
\hline Upper & 8 & $3(25.0)$ & $5(22.7)$ & 0.881 \\
\hline Middle & 21 & $8(66.7)$ & 13(59.1) & \\
\hline Lower & 5 & $1(8.3)$ & $4(18.2)$ & \\
\hline \multicolumn{5}{|c|}{ Differentiation grade } \\
\hline High & 12 & $8(66.7)$ & $4(18.2)$ & 0.008 \\
\hline medium+low & 22 & $4(33.3)$ & 18(81.8) & \\
\hline
\end{tabular}

\section{$P$ value}

Note: Values in parentheses indicate percentage values. The bold number represents the $P$ values with significant differences. 
Table 2

Expression of p62 in high, medium and low

differentiation ESCC

\begin{tabular}{|lllll|}
\hline & \multicolumn{3}{l}{ p62 expression } & P value \\
\cline { 1 - 4 } Differentiation & Total & Low & High & 0.009 \\
\cline { 1 - 4 } low & 5 & 0 & 5 & \\
\cline { 1 - 4 } medium & 5 & 2 & 3 & \\
\cline { 1 - 4 } High & 5 & 5 & 0 & \\
\hline
\end{tabular}

\section{Downregulation of p62 impaired the migration and invasion of ESCC cells in vitro}

Next, we explored the cellular function of p62 in ESCC using EC109 cells, a ESCC cell line. EC190 cells with p62 knockdown (KD) of (p62 ${ }^{\mathrm{KD}}$ ) were generated by CRISPR/Cas9 technology and validated by Western blot (Fig. 2A). Compared with wild type control EC109 cells, the p62 ${ }^{\mathrm{KD}}$ cells exhibited reduced invasiveness (Fig. 2B and 2C) and migration (Fig. 2D) abilities. High-content analysis also showed that the cell speed in $\mathrm{p} 62^{\mathrm{KD}}$ group was significantly lower than that of wild group (Fig. 2E). These results indicate that p62 plays an important role in mediating the progression and metastasis of ESCC.

\section{p62 mediates EMT and F-actin polarization in ESCC cells}

We further determined whether p62 regulates EMT in EC109 cells. As shown in Fig. 3A and 3B, the expression of EMT-related indicators including N-cadherin, Smad2/3, and Slug were downregulated in p $62^{\mathrm{KD}}$ group, suggesting a role of p62-mediated EMT in ESCC. In addition, rhodamine-phalloidin staining also showed that the expression and polarity distribution of F-actin were decreased, the cell edges were blurred, the skeletal areas were significantly reduced, and the structure of the F-actin filaments were destroyed in $\mathrm{p} 62^{\mathrm{KD}}$ cells, compared with that in wild type cells (Fig. 3C). These results indicate that p62 is required for maintaining F-actin polarization and F-actin filament integrity in ESCC. Moreover, highcontent analysis showed that the cell areas of $\mathrm{p} 62^{\mathrm{KD}}$ cells were significantly smaller than that of wild type cells, while the cell roundness p62 ${ }^{\mathrm{KD}}$ cells was significantly higher than wild type ones (Fig. 3D). These results indicate a critical role of p62 controlling the cell morphology.

\section{Nrf2 acts as a downstream effector of p62-mediated EMT and F-actin polarization in ESCC cells}


Considering the aforementioned positive feedback loop in which p62 stabilizes Nrf2, which in turn upregulates p62 expression (16), to this end, we questioned whether the interaction of p62 and Nrf2 contributes to the progression and metastasis of ESCC. We analyzed the expression profile of Nrf2 in various human tumors using the GEPIA database. We found that Nrf2 expression was higher in esophageal cancer comparing to that in matched normal tissues (Fig. S1'). Next, we generated Nrf2 or Nrf2 and p62 double knockdown ESCC cell by CRISPR/Cas9 technology (Fig. 4A). As shown in p62 KD group, Nrf2 ${ }^{\mathrm{KD}}$ or Nrf2 and p62 double knockdown (p62 ${ }^{\mathrm{KD}}$ :Nrf2 ${ }^{\mathrm{KD}}$ ) also downregulated the expression of $\mathrm{p}$-Smad2/3 and Slug, however, the inhibitory effect of p62 ${ }^{\mathrm{KD}}: \mathrm{Nrf2}{ }^{\mathrm{KD}}$ was more obvious (Fig. 4A).

In addition, we compared the impact of $\mathrm{p} 62^{\mathrm{KD}}, \mathrm{Nrf} 2^{\mathrm{KD}}$, and $\mathrm{p} 62^{\mathrm{KD}}$ : $\mathrm{Nrf} 2^{\mathrm{KD}}$ on the cellular F-actin dynamics. Rhodamine-phalloidin staining showed that $\mathrm{Nrf} 2^{\mathrm{KD}}, \mathrm{p} 62^{\mathrm{KD}}$ : $\mathrm{Nrf} 2^{\mathrm{KD}}$ or $\mathrm{p} 62^{\mathrm{KD}}$ phenocopy associated collapse of F-actin filament cytoskeleton characterized by decreased expression and polarity of F-actin, blurred cell edges, and reduced skeletal areas (Fig. 4B). High-content analysis showed that $\mathrm{p} 62^{\mathrm{KD}}, \mathrm{Nrf2} 2^{\mathrm{KD}}$ or p62 ${ }^{\mathrm{KD}}$ : $\mathrm{Nrf2} 2^{\mathrm{KD}}$ decreased cell areas while increasing cell roundness although the effect of $\mathrm{Nrf2}{ }^{\mathrm{KD}}$ was not statistically significant (Fig. 4C). These results indicate that $\mathrm{p} 62$ plays a critical role in mediating EMT associated with F-actin remodeling in ESCC cells. Mechanistically, it is likely that Nrf2 serves as a downstream effector of p62 and intentifies p62-mediated actions via a positive feedback upregution of p62 expression as described in the other cell types (17).

\section{Nrf2 serves as a downstream effector of p62-mediated growth and metastasis of ESCC cells in vitro}

To determine the functional significance of p62 and Nrf2 interaction in ESCC, we examined the impact of $\mathrm{p} 62^{\mathrm{KD}}$ and/or Nrf2 ${ }^{\mathrm{KD}}$ on the migration and invasion abilities of ESCC cells in vitro using wound-healing and transwell assays. p62 $2^{\mathrm{KD}}, \mathrm{Nrf} 2^{\mathrm{KD}}$ or $\mathrm{p} 62^{\mathrm{KD}}$ : $\mathrm{Nrf} 2^{\mathrm{KD}}$ effectively reduced the invasiveness and migration of ESCC cells (Fig. 5A and 5B), which were verified by high-content analysis (Fig. 5C and 5D). These results suggest that both p62 and Nrf2 play an important role in ESCC. Indeed, knockdown of p62 and/or Nrf2 significantly inhibited the clone formation ability of ESCC cells in vitro (Fig. 6A). The xenograft assay in vivo revealed that $\mathrm{p} 62^{\mathrm{KD}}, \mathrm{Nrf2} 2^{\mathrm{KD}}$ or $\mathrm{p} 62^{\mathrm{KD}}$ : Nrf2 ${ }^{\mathrm{KD}}$ suppressed the tumorigenesis of $\mathrm{EC} 109$ cells and the tumor suppressive effect of $\mathrm{p} 62^{\mathrm{KD}}$ : Nrf2 ${ }^{\mathrm{KD}}$ was the strongest (Fig. 6B). Moreover, p62 ${ }^{\mathrm{KD}}, \mathrm{Nrf} 2^{\mathrm{KD}}$, or p62 ${ }^{\mathrm{KD}}$ :Nrf2 ${ }^{\mathrm{KD}}$ significantly decreased the pulmonary metastasis of EC109 cells in nude mice (Fig. 6C). $\mathrm{IHC}$ showed that $\mathrm{p} 62^{\mathrm{KD}}, \mathrm{Nrf} 2^{\mathrm{KD}}$ or $\mathrm{p} 62^{\mathrm{KD}}: \mathrm{Nrf} 2^{\mathrm{KD}}$ decreased the expression levels of Vimentin in tumors and the expression of Vimentin was positively correlated with the severity of tumorigenesis (Fig. 6B-E). Importantly, Nrf2 ${ }^{\mathrm{KD}}$ downregulated the expression of p62 in tumors (Fig. 6E). In conclusion, these results indicate that p62 and Nrf2 promote the development and metastatsis of ESCC. At the molecular level, Nrf2 serves as a downstream effector of p62 and may also function as a positive regulator p62 per se, thereby contributing to the pathogenesis of ESCC. 


\section{Discussion}

In this study, we demonstrate that p62 and Nrf2 promote EMT, the invasion ability of ESCC cells, and metastasis of ESCC via a mechanism by which p62 and Nrf2 form a positive feedback loop to faciliate each other's function. Our findings also suggest that p62 and Nrf2 may be not only therapeutic targets but also potential prognostic markers for ESCC.

EMT is an important mechanism regulating the initial stage of tumor metastasis. Inhibiting EMT is an important therapeutic strategy for clinical tumor therapy (18). The occurrence and development of EMT involve different signaling pathways and signal crosstalk. Our results revealed that both p62 and Nrf2 mediate EMT in ESCC in a synergistic manner. Consistent with our findings, previous studies showed that p62 promotes the occurrence and development of bladder cancer by upregulating the expressions of Nrf2 (19); and p62 promotes the proliferation and migration of prostate cancer cells by activating the Keap1/Nrf2/ARE pathway (20). In addition, HMGB1 induces glioblastoma (GBM) cell EMT by upregulation of p62 and stabilizes Snail by GSK-3 $\beta$ mediated proteasome degradation (21). These results support that p62 and/or Nrf2-mediated EMT contributes to ESCC metastasis.

In addition, it has been shown that EMT is associated with actin cytoskeletal remodeling. F-actin filament is an important component of the cytoskeleton and the dynamic remodeling of these filaments provide the impetus for cell invasion and migration (22-24). The polymerization and depolymerization of F-actin filaments and cell migration are also associated with neoplasm metastasis (25). In the present study, we found that there is a synergy between p62 and Nrf2 in maintaining F-actin polymerization while promoting EMT in ESCC, which is similar to the other report that shows enhanced p62-nrf2 feedback loop contributes to malignant transformation of human keratinocytes (17). Importanly, our results suggest that Nrf2 likely serves as a downstream effector of p62 and intentifies p62-mediated actions via a positive feedback upregution of p62 expression as described in the other cells(20). To sum up, we speculate that p62 and Nrf2 play an important role in mediating ESCC metastasis by inducing EMT.

Infinite proliferation is a sign of cancer cells. As far as cancer cell proliferation is concerned, both p62 and Nrf2 play an important role in regulating cancer cell proliferation (26-28). However, the role of p62 and Nrf2 in the proliferation of cancer cells under ESCC is still unclear. Up to now, only studies have reported that p62 can resist the apoptosis of ESCC cells and promote the proliferation of ESCC cells by activating protein kinase $\mathrm{C}$ iota (PKCiota)-S-phase kinase related protein 2(SKP2) pathway under serum starvation (29). In ESCC, Nrf2 is the direct target gene of miR-27b-3p, which can inhibit the proliferation of ESCC cells by inhibiting Nrf2 (30). In this study, we also found that knockdown of p62 or Nrf2 could inhibit proliferation of ESCC cells. However, knocking down p62 and Nrf2 at the same time has the best inhibitory effect, and they may have synergistic effect on the proliferation of ESCC cells.

There are several limitations in our study. Firstly, the effect of p62 or Nrf2 knockdown but not double p62 and Nrf2 knockdown on EMT and metastasis of CEC2 cells are determined. Secondly, the interaction between p62 and Nrf2 in EMT and metastasis of ESCC has not been fully dissected. Finally, the 
correlation between the expression levels of p62 or Nrf2 and the survival rate of ESCC patients remains to be established. Further investigation of these issues will provide novel insight into the pathogenesis of ESCC and valuable information for targeting p62 and/or Nrf2 to treat ESCC.

\section{Conclusion}

In summary, we demonstrated that the p62 and Nrf2 constitutes an important regulatory mechanism in ESCC(Figure 7). These results indicate that p62 and Nrf2 promote EMT and metastasis of ESCC in a synergistic manner. Simultaneously targeting of p62 and Nrf2 may have a therapeutic potential in treating ESCC.

\section{Methods}

\section{Cell culture and treatments}

293T cell line was donated by Professor Sheng Wang of Beijing University of Technology. CEC2 and EC109 cell lines were provided by Dr. Jintao Li at Beijing University of Technology. These cells were cultured in high-glucose Dulbecco's modified Eagle's medium (Gibco; Thermo Fisher Scientific, Inc.) supplemented with $10 \%$ fetal bovine serum (Beyotime Institute of Biotechnology), $100 \mathrm{mg} / \mathrm{mL}$ streptomycin and $100 \mathrm{U} / \mathrm{mL}$ penicillin (Beyotime Institute of Biotechnology) in a $37^{\circ} \mathrm{C}$ and $5 \% \mathrm{CO}_{2}$ atmosphere.

\section{Tissue microarray and immunohistochemistry (IHC)}

The tissue microarray was prepared by Wuhan Iwill Biological Technology Co.Ltd. It contains 34 ESCC tissues (tumor) and corresponding adjacent normal esophageal tissues (AT). The scores are based on the sum of the percent staining area plus staining intensity. Clinical information was provided by the commercial source. The expression of p62 in tissue microarray was summarized in Table 1. The paraffinembedded esophageal tissues were obtained from the Department of Oncology, Affiliated Taihe Hospital of the Hubei University of Medicine. These include poorly differentiated $(n=5)$, moderately differentiated $(n=5)$, and highly differentiated $(n=5)$ esophageal squamous cell carcinomas (It's classified by pathology). Briefly, 4- $\mu$ m-thick sections mounted on glass slides were processed for immunohistochemistry $(\mathrm{IHC})$. After dewaxing and hydration, endogenous peroxidase was inactivated by $3 \%$ methanol hydrogen peroxide for $10 \mathrm{~min}$. Then $10 \%$ goat serum albumin (Beijing Solarbio Science \& Technology Co., Ltd.) was used to block nonspecific binding by incubating sections for $2 \mathrm{~h}$ at room temperature while gently tilting the sections without washing them, followed by incubation with p62 (1:200; cat. no. 55274; ProteinTech Group, Inc.), Nrf2 (1:200; cat. no. 55274; ProteinTech Group, Inc.) and Vimentin (1:200; cat. no. AF1975; Beyotime Institute of Biotechnology) anti-bodies at $4{ }^{\circ} \mathrm{C}$ overnight in a moist chamber. After being washed three times with phosphate-buffered saline (PBS), the sections were incubated with a secondary antibody (1:200; cat. no. A0208; Beyotime Institute of Biotechnology at room 
temperature) for $1 \mathrm{~h}$ and rinsed in PBS. Diaminobenzidine (DAB) was used as a chromogen, and sections were counterstained with hematoxylin. Negative controls were obtained by incubating specimens with PBS instead of the primary antibody. All patients signed informed consent forms prior to the study. Brown particles in cells are thought to be positive signals; the staining intensity was determined and scored by two pathologists. Please refer to Table 2 for scoring criteria.

\section{Establishment of p62 knockdown, Nrf2 knockdown, p62 and $\mathrm{Nrf2}$ double knockdown stable cell lines}

To produce p62 knockdown, Nrf2 knockdown, p62 and Nrf2 double knockdown stable cell lines, p62 and Nrf2 deletion mutants were first constructed. Oligo DNA sequences were designed in the target DNA region using the CRISPR Design online tool, the sequences were shown in table 2 . The primer dimers of oligo DNAs were annealed with the pGL3-U6-sgRNA-PGK plasmids. The plasmids were transfected into cells using an electro cell manipulator electroporator (Boston Industries, Inc.), and after $48 \mathrm{~h}, 2 \mu \mathrm{g} / \mathrm{mL}$ puromycin (cat. no. ST551; Beyotime Institute of Biotechnology) at room temperature was added to the medium for 3 days. When the cells reached the logarithmic stage, they were digested and a single cell was cultured in a 96-well plate for 15 days, and then transferred to a 6-well plate for culture. Cells were collected and genomic DNA was extracted. T7E1 endonuclease kit (cat. no. E001S; VIEWSOLID BIOTECH) was used to detect the target effeciency. Positive cell lines were selected for subsequent experiments.

\section{RNA extraction and reverse transcription PCR}

Total RNA was extracted from cells by TRIzol (Beyotime Institute of Biotechnology). Reverse transcription was carried out using reverse transcriptase (Takara Bio, Inc.) according to the manufacturer's instructions. The levels of E-cadherin, $\mathrm{N}$-cadherin, Vimentin and Snail were detected by PCR $\left(95^{\circ} \mathrm{C}\right.$ for 3 min; $95^{\circ} \mathrm{C} 30 \mathrm{SEC} ; 58{ }^{\circ} \mathrm{C} 30 \mathrm{SEC} ; 72{ }^{\circ} \mathrm{C} 30 \mathrm{sec} ; 72{ }^{\circ} \mathrm{C}$ for $5 \mathrm{~min}$; for 30 cycles) $\otimes G A P D H$ serves as an internal reference. Gene-specific primers are shown in table 2 in the supplemental file.

\section{Western blot analysis}

Cells of different treatment groups were incubated in T25 culture bottles. Total protein was isolated from the cells using RIPA buffer with $1 \%$ phenylmethyl sulfonylfluoride (PMSF). The protein concentration was determined by BCA protein detection kit (Beyotime Institute of Biotechnology). 30 $\mu$ g total protein in each sample was isolated in $12 \%$ tris-glycine SDS gel, and transfer to $0.22 \mu \mathrm{m}$ polyvinylidene fluoride (PVDF) membrane (Beijing BeiFang Tongzheng Biotechnology Development Co. Ltd). Then the membrane was sealed in TBST with $5 \%$ skim milk powder for $2 \mathrm{~h}$, and incubated overnight with the corresponding primary antibody (diluted according to instructions), TBST was used for washing three times, each wash took about $10 \mathrm{~min}$, The membrane was incubated at room temperature for $2 \mathrm{~h}$ with HRP-conjugated secondary antibody (1:5000; Beyotime Institute of Biotechnology). The binding antibody was observed 
with an enhanced chemiluminescence kit (Beyotime Institute of Biotechnology) and imaging system (BioRad, USA).

\section{F-actin staining}

Cells from different treatment groups were cultured in 96 -well plates until $50 \%$ confluent, and fixed with $4 \%$ paraformaldehyde. Cells were permeated with $0.5 \%$ Triton X-100 and incubated in the dark for 30 minutes with $100 \mathrm{nM}$ of rhodamine-phalloidin (Cytoskeleton, Inc.) at room temperature. Then the nuclei were stained using DAPI (Thermo Fisher Scientific, Inc.). Lastly, the cells were observed and photographed using High-Content Analysis (HCA; PerkinElmer, Inc.), and analyzed using the harmony software.

\section{Wound healing assay}

Cell migration was detected by wound healing assay. Cells were cultured in 6-well plates until arrived at 80 to 90 percent of confluence. A $200 \mu \mathrm{L}$ pipette tip was used to produce scratches. Then the cells were cultured in serum-free medium and photographed with an inverted microscope (Leica Corporation) at 0 , $24,48,72$ and $96 \mathrm{~h}$ after scratching. The wound healing rate was measured as follows: [(empty area $0 \mathrm{~h}$ empty area $\mathrm{xh}$ )/ empty area $0 \mathrm{~h}] \times 100$.

\section{Invasion assay}

The matrigel (BD Biosciences, CA, USA) was added to each upper chamberaccording to the manufacturer's instructions. $1 \times 10^{5} \mathrm{ESCC}$ cells were inoculated into the upper chamber. Medium containing $10 \%$ FBS was added to the lower chamber. After incubation at $37^{\circ} \mathrm{C}$ for $72 \mathrm{~h}$, the non-invasive cells were gently wiped with a cotton swab from the top of the matrigel. The invasive cells at the bottom of the chamber were fixed in methanol and stained with $0.1 \%$ crystal violet. The cells in five random fields were counted with inverted microscope (Leica Corporation) and quantified.

\section{Colony formation assay}

A total of 500 cells were cultured in 6-well plates for 2 weeks. After the cells form visible clones, the cells were fixed with methanol for $20 \mathrm{~min}$ and stained with crystal violet for $30 \mathrm{~min}$. The numbers of clonesin each group were counted with an inverted phase contrast microscope (Leica Corporation). Three independent replicates were performed.

\section{Xenograft assay}


All animal experiments were approved by Animal Ethics Committee at Animal ethics committee of the Hubei University of Medicine, all animal procedures and animal care were conducted in accordance with the guidelines for institutional animal research. Female BALB/c-nu mice aged 4 weeks were selected (purchased from Shanghai experimental animal center of Chinese academy of sciences). They were fed under specific, non-pathogenic conditions and given sterilized food and water. $1 \times 10^{7}$ wild, p62 ${ }^{\mathrm{KD}}, \mathrm{Nrf} 2^{\mathrm{KD}}$, and p62 ${ }^{\mathrm{KD}}$ :Nrf2 ${ }^{\mathrm{KD}} \mathrm{EC} 109$ cells were subcutaneously injected into the left armpit, right armpits, left groin and right groin of 4 nude mice, respectively. After 4 weeks, the mice were killed, the subcutaneous tumor was removed and fixed with $10 \%$ paraformaldehyde for further analysis. Similarly, The same number of wild, p62 ${ }^{\mathrm{KD}}, \mathrm{Nrf2} 2^{\mathrm{KD}}$, and p62 ${ }^{\mathrm{KD}}$ :Nrf2 ${ }^{\mathrm{KD}} \mathrm{EC} 109$ cells were inoculated into the tail vein of 4-week-old female nude mice. After 8 weeks, the visceras of all the mice were dissected and fixed in formalin for further analysis.

\section{Statistical analysis}

The values are shown as the means \pm S.D. for triplicate experiments. To statistically analyze the significance between two groups or greater than two groups, the Student's t-test or the ANOVA test was appropriately used, respectively. The Fishers exact test was used to analyze the relationships among PHLDA2 expression and clinical characteristics of ESCC patients. $P<0.05$ was considered statistically significant. SPSS 25.0 software was used for all statistical analyses.

\section{Abbreviations}

P62: Sequestosome 1; Nrf2: Nuclear factor erythroid 2-related factor 2; ESCC: Esophageal squamous cell carcinoma; AC: Adenocarcinoma; SCC: Squamous cell carcinoma; EMT: Epithelial mesenchymal transion; ECM: Extracellular matrix; KEAP1: Kelch-like ECH associated protein 1; ESCA: Esophageal carcinoma

\section{Declarations}

\section{Acknowledgements}

Not applicable.

\section{Authors' contributions}

YD conceived and designed the experiments, reviewed and revised manuscripts; XYC conducted, RT-PCR, Western blot, proliferation, migration, invasion, F-actin staining; colony formation, xenograft assays, analysis and wrote the manuscript; LY performed Western blots, Transfection and knocking down experiments and analysis; JR and SW performed Western blots, xenograft assays and 
immunohistochemistry; YJT participated in the analysis of experimental data, revised manuscripts. All authors have read and approved the manuscript.

\section{Funding}

The present study was supported by the National Natural Science Foundation of China (81602297, 81960473), Guangxi Zhuang Autonomous Natural Science Foundation (2018JJB140322), the project of science and technology innovation for Postgraduates of Hubei Medical College (YC2019013, YC2019018), Knowledge Innovation Program of Science and Technology Department of Hubei Province (2018ACA162).

\section{Availability of Data and Materials}

All data generated or analysed during this study are included in this published article and its supplementary information files.

\section{Ethics approval and consent to participate}

The study is reported in accordance with ARRIVE guidelines. All animal experiments were approved by Animal Ethics Committee at Animal ethics committee of the Hubei University of Medicine, all animal procedures and animal care were conducted in accordance with the guidelines for institutional animal research.

\section{Consent for publication}

Not applicable.

\section{Competing interests}

The authors declare that they do not have financial or non-financial competing interests.

\section{References}

1. Ferlay J, Soerjomataram I, Dikshit R, Eser S, Mathers C, Rebelo M, Parkin DM, Forman D and Bray F: Cancer incidence and mortality worldwide: Sources, methods and major patterns in GLOBOCAN 2012. International Journal of Cancer 136: E359-E386, 2015.

2. Melina A, Isabelle $S$, Jacques $F$ and David F: Global incidence of oesophageal cancer by histological subtype in 2012. Gut 64: 381-387, 2015. 
3. Arjun P, Gibson MK, Jobe BA and Luketich JD: Oesophageal carcinoma. Lancet 381: 400-412, 2013.

4. Antoine A, Robb WB and Christophe M: Esophageal carcinoma. New England Journal of Medicine 372: 1470-1473, 2015.

5. Samy L, Jian X and Rik D: Molecular mechanisms of epithelial-mesenchymal transition. Nature Reviews Molecular Cell Biology 15: 178-196, 2014.

6. Aiello NM and Kang Y: Context-dependent EMT programs in cancer metastasis. 216: 1016-1026, 2019.

7. Goossens S, Vandamme N, Van Vlierberghe P and Berx G: EMT transcription factors in cancer development re-evaluated: Beyond EMT and MET. Biochimica et biophysica acta Reviews on cancer 1868: 584-591, 2017.

8. Xu LZ, Li SS, Zhou W, Kang ZJ, Zhang QX, Kamran M, Xu J, Liang DP, Wang CL and Hou ZJ: p62/SQSTM1 enhances breast cancer stem-like properties by stabilizing MYC mRNA. Oncogene 36: 304, 2016.

9. Duran A, Hernandez E, Reina-Campos M, Castilla E, Subramaniam S, Raghunandan S, Roberts L, Kisseleva T, Karin M and Diaz-Meco M: p62/SQSTM1 by Binding to Vitamin D Receptor Inhibits Hepatic Stellate Cell Activity, Fibrosis, and Liver Cancer. Cancer Cell 30: 595-609, 2016.

10. Mohamed A, Ayman A, Deniece J, Wang T, Kovach C, Siddiqui MT and Cohen C: P62/Ubiquitin IHC Expression Correlated with Clinicopathologic Parameters and Outcome in Gastrointestinal Carcinomas. Frontiers in Oncology 5: 70, 2015.

11. Matthieu B, Valérie P, Ashish J, Raymonde A, Terje J, Lionel L, Patrice $C$ and Isabelle B: SQSTM1/p62 regulates the expression of junctional proteins through epithelial-mesenchymal transition factors. Cell Cycle 14: 364-374, 2015.

12. Shen H, Yang Y, Xia S, Rao B and Zhang J: Blockage of Nrf2 suppresses the migration and invasion of esophageal squamous cell carcinoma cells in hypoxic microenvironment. Diseases of the Esophagus 27: 2014.

13. Copple IM, Lister A, Obeng AD, Kitteringham NR, Jenkins RE, Layfield R, Foster BJ, Goldring CE and Park BK: Physical and Functional Interaction of Sequestosome 1 with Keap1 Regulates the Keap1Nrf2 Cell Defense Pathway. Journal of Biological Chemistry 285: 16782-16788,

14. Umemura A, He F, Taniguchi K, Nakagawa H, Yamachika S, Font-Burgada J, Zhong Z, Subramaniam S, Raghunandan S, Duran A, et al: p62, Upregulated during Preneoplasia, Induces Hepatocellular Carcinogenesis by Maintaining Survival of Stressed HCC-Initiating Cells. Cancer Cell 29: 935-948, 2016.

15. Pölönen P, Jawahar Deen A, Leinonen HM, Jyrkkänen HK, Kuosmanen S, Mononen M, Jain A, Tuomainen T, Pasonen-Seppänen S, Hartikainen JM, et al: Nrf2 and SQSTM1/p62 jointly contribute to mesenchymal transition and invasion in glioblastoma. 38: 7473-7490, 2019.

16. Wei Y, Liu D, Jin X, Gao P and Zhang N: PAãu SHA inhibits the growth of doxorubicin-resistant MCF/ADR human breast cancer cells by downregulating Nrf2/p62. Cancer Med 5: 3520-3531, 2016. 
17. Wu X, Sun R, Wang H, Yang B, Wang F, Xu H, Chen S, Zhao R and Pi J: Enhanced p62-NRF2 Feedback Loop due to Impaired Autophagic Flux Contributes to Arsenic-Induced Malignant Transformation of Human Keratinocytes. 2019: 1038932, 2019.

18. Chen C, Liang QY, Chen HK, Wu PF, Feng ZY, Ma XM, Wu HR and Zhou GQ: DRAM1 regulates the migration and invasion of hepatoblastoma cells via autophagy-EMT pathway. Oncology letters 16: 2427-2433, 2018.

19. Li T, Jiang D and Wu K: p62 promotes bladder cancer cell growth by activating KEAP1/NRF2dependent antioxidative response. Cancer science 111: 1156-1164, 2020.

20. Jiang G, Liang X, Huang Y, Lan Z, Zhang Z, Su Z, Fang Z, Lai Y, Yao W, Liu T, et al: p62 promotes proliferation, apoptosis-resistance and invasion of prostate cancer cells through the Keap1/Nrf2/ARE axis. Oncol Rep 43: 1547-1557, 2020.

21. Li H, Li J, Zhang G, Da Q, Chen L, Yu S, Zhou Q, Weng Z, Xin Z, Shi L, et al: HMGB1-Induced p62 Overexpression Promotes Snail-Mediated Epithelial-Mesenchymal Transition in Glioblastoma Cells via the Degradation of GSK-3beta. Theranostics 9: 1909-1922, 2019.

22. Dart AE and Gordon-Weeks PR: The Role of Drebrin in Cancer Cell Invasion. 2017.

23. Wen Q and Janmey PA: Polymer physics of the cytoskeleton. Current opinion in solid state \& materials science 15: 177-182, 2011.

24. Annie, Cristhine, Moraes, Sousa-Squiavinato, Murilo, Ramos, Rocha, Pedro, Barcellos-de-Souza and Waldemir: Cofilin-1 signaling mediates epithelial-mesenchymal transition by promoting actin cytoskeleton reorganization and cell-cell adhesion regulation in colorectal cancer cells. Biochimica Et Biophysica Acta Molecular Cell Research 2018.

25. Xie L, Li LY and Zheng D: F806 Suppresses the Invasion and Metastasis of Esophageal Squamous Cell Carcinoma via Downregulating F-Actin Assembly-Related Rho Family Proteins. 2018: 2049313, 2018.

26. PInen P, Deen AJ, Leinonen HM, Jyrkknen HK and Levonen AL: Nrf2 and SQSTM1 /p62 jointly contribute to mesenchymal transition and invasion in glioblastoma. Oncogene 38: 1-18, 2019.

27. Jiang G, Liang X, Huang Y, Lan Z, Zhang Z, Su Z, Fang Z, Lai Y, Yao W and Liu T: p62 promotes proliferation, apoptosisresistance and invasion of prostate cancer cells through the Keap1/Nrf2/ARE axis. Oncology Reports 2020.

28. Hwang SK, Jeong YJ and Chang YC: PDCD4 inhibits lung tumorigenesis by the suppressing p62-Nrf2 signaling pathway and upregulating Keap1 expression. American journal of cancer research 10: 424-439, 2020.

29. Shi C, Pan BQ, Shi F, Xie ZH, Jiang YY, Shang L, Zhang Y, Xu X, Cai Y and Hao JJ: Sequestosome 1 protects esophageal squamous carcinoma cells from apoptosis via stabilizing SKP2 under serum starvation condition. Oncogene 37: 2018.

30. Han M, Li N, Li F, Wang H and Ma L: MiR-27b-3p exerts tumor suppressor effects in esophageal squamous cell carcinoma by targeting Nrf2. Human Cell 33: 641-651, 2020. 
Figures

\section{Figure 1}

A

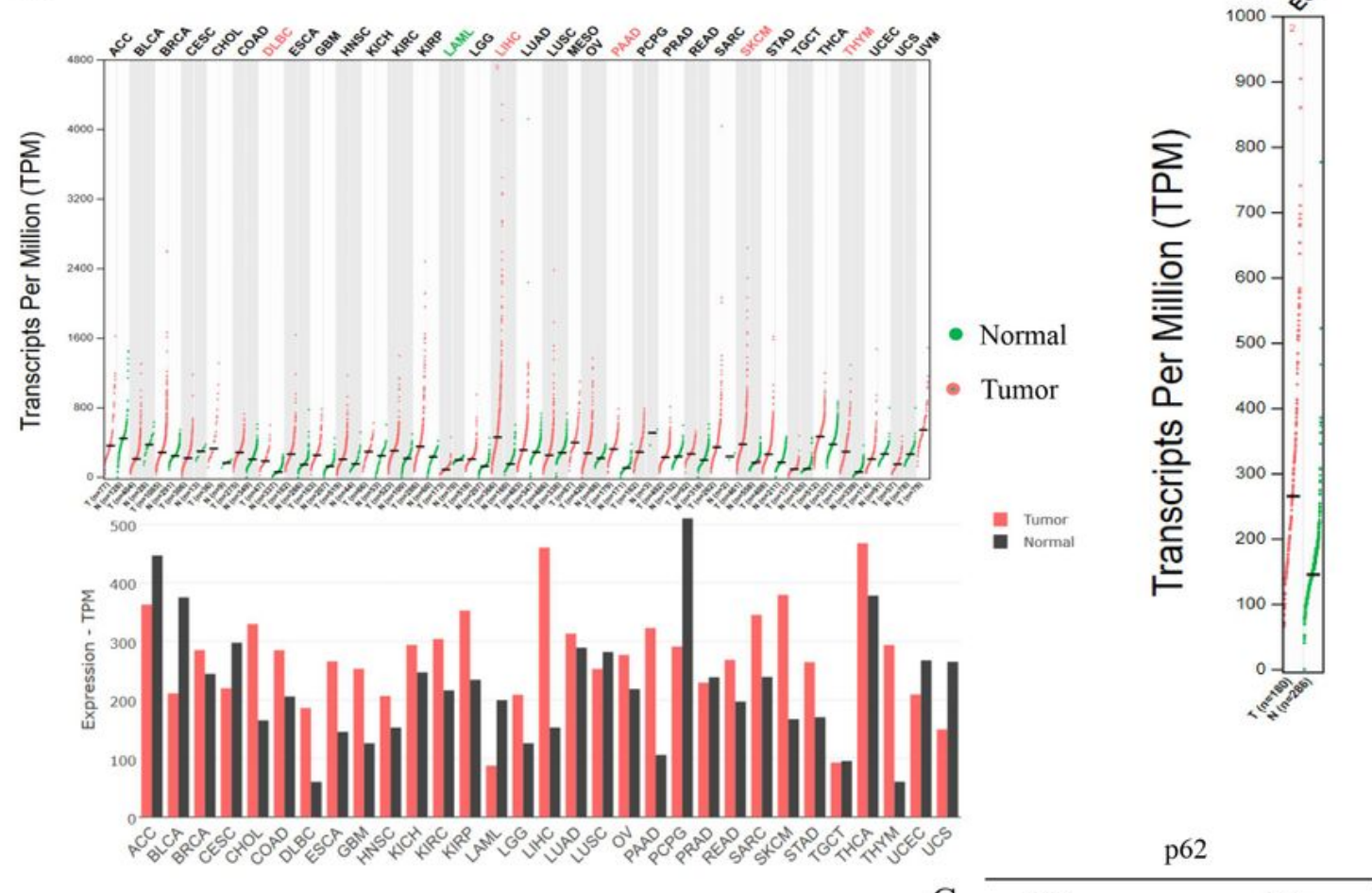

B
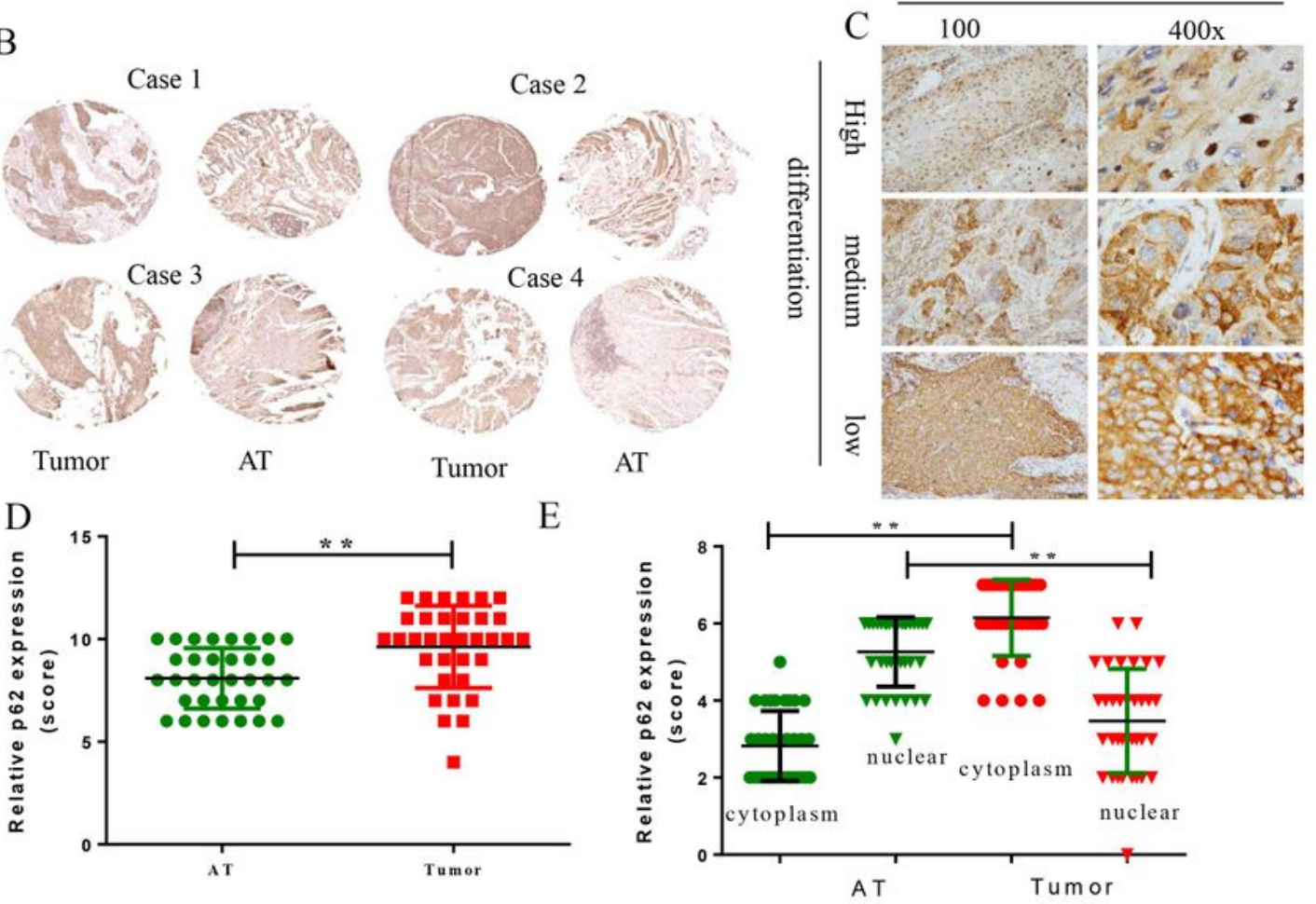

Figure 1

P62 expression is associated with esophageal cancer. (A) P62/Sequestosome 1 expression was higher in esophageal carcinoma (ESCA) compared to the matched normal tissues (GEPIA). (B) Representative images of p62 staining (brown) ESCC tissue samples (on the lest) with corresponding adjacent normal 
esophageal tissues (AT, on the right, $n=34$ ). (C) Immunohistochemical images of representative $p 62$ tumor tissues. From top to bottom: low, medium and high expression of p62,in which high ,medium and low respectively represent their corresponding degree of pathological differentiation. $(n=5)$. (D, E) Expression score of p62 in esophageal squamous cell carcinoma tissue microarray, the scores are based on the sum of percent staining area plus staining intensity Data are shown as mean $\pm S D$, $* * P<0.01$.

\section{Figure 2}

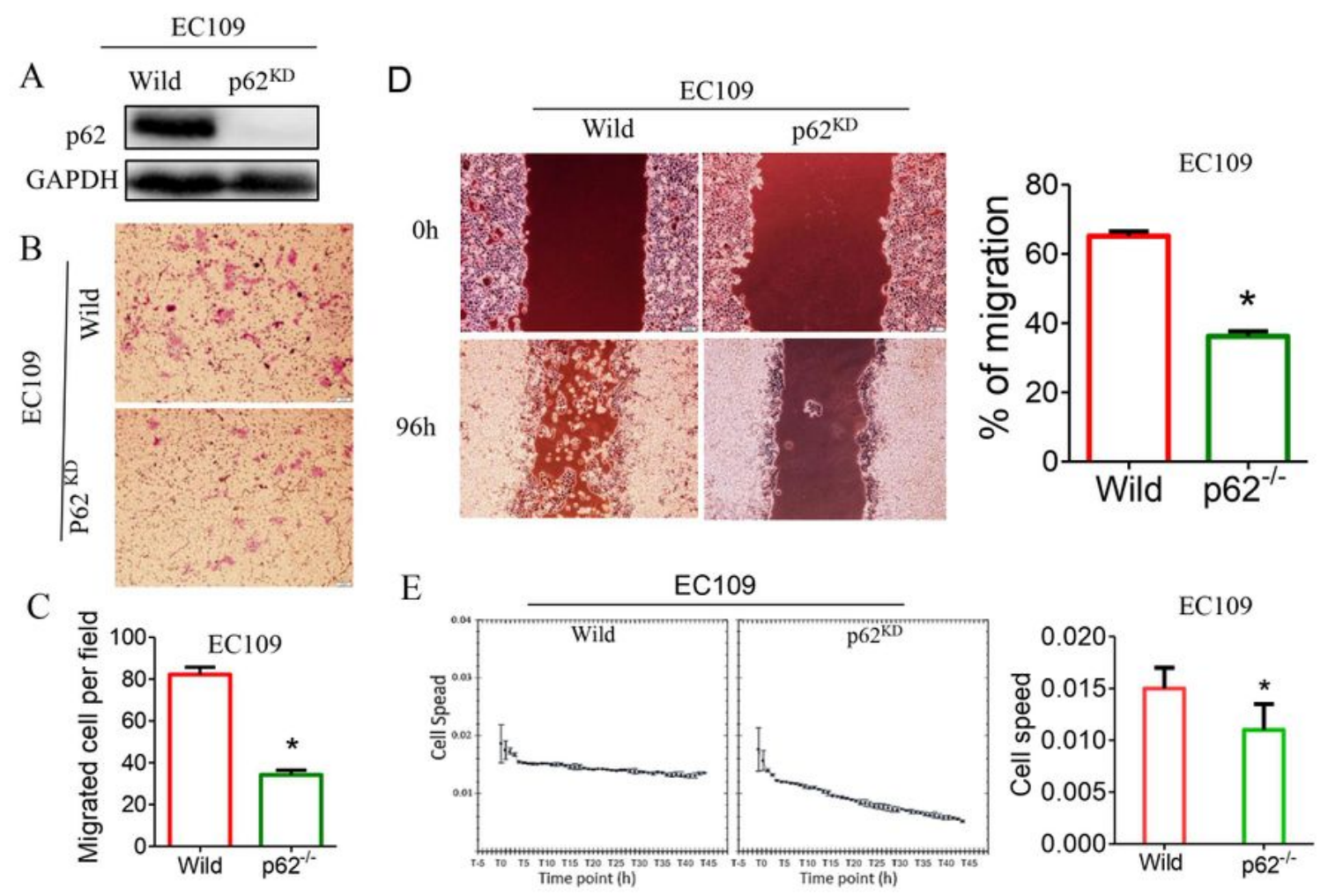


Knockdown of p62 inhibits migration and invasion of ESCC cells in vitro. (A) The expression level of p62 protein in EC109 cells decreased after p62 was knocked out by CRISPR/Cas9 gene editing. Cell invasion $(B, C)$ and migration(D) decreased after p62 gene knockdown. (E) High - content analysis showed that p62 gene knockdown inhibited the migration of EC109 cells. Data are shown as mean $\pm S D, * P<0.05$.

\section{Figure 3}

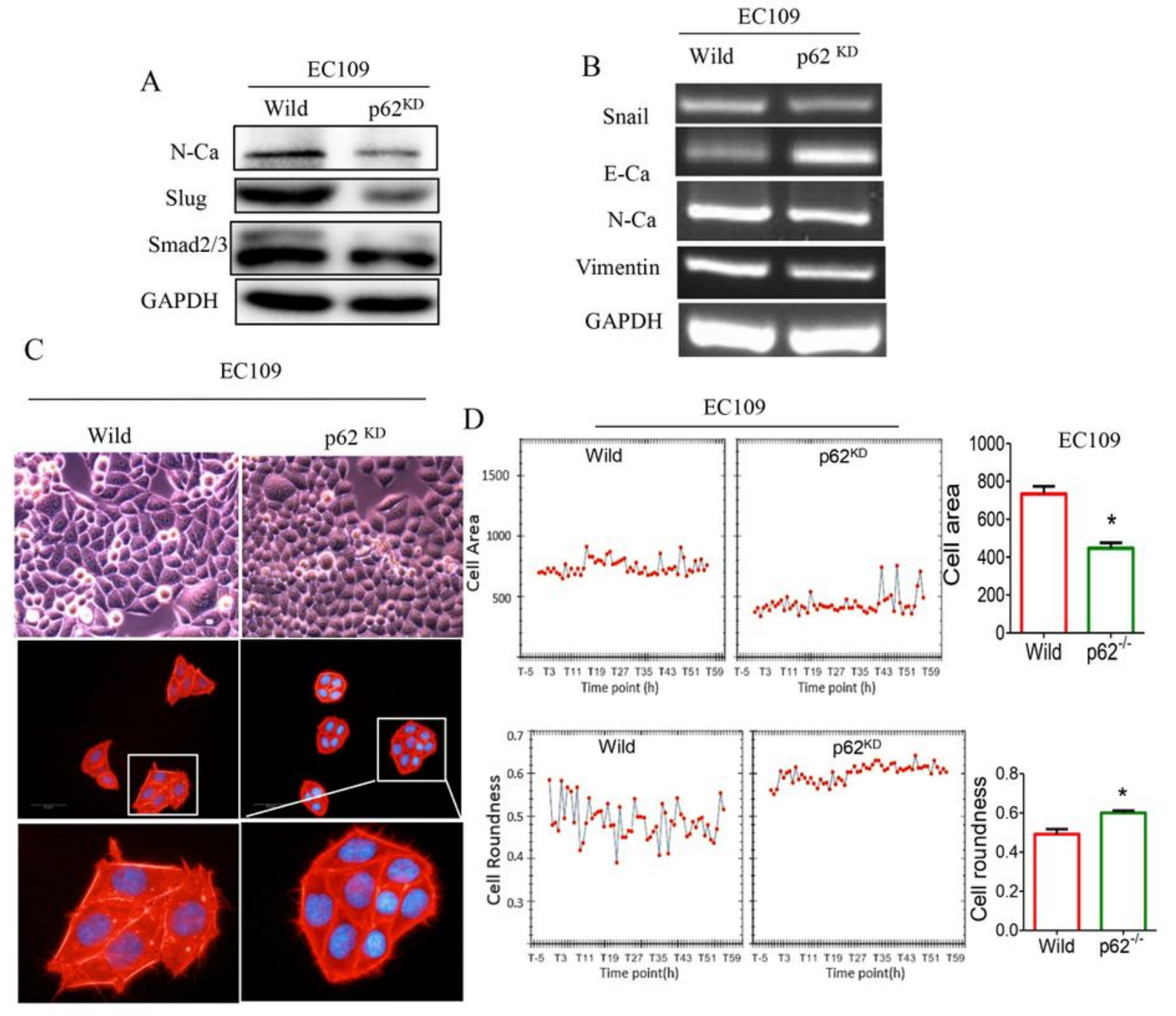

Figure 3 
After p62 knockdown, EMT and F-actin polarization of ESCC cells were inhibited and autophagy was promoted. P62 deletion down-regulated the expression levels of various EMT-related markers (A, B). (C) Morphology of ESCC cells in P62 p62KD and wild-type group (400x). The p62 knockdown suppressed Factin polarization in EC109 cells. The distribution of F-actin (red) between wild and p62KD EC109 cells was determined by rhodamine-phalloidin staining. The nuclei were stained with DAPI (blue). (D) Highcontent analysis showed that the cell areas decreased and the cell roundness increased after the p62 gene was knockdown in EC109 cells. Data are shown as mean \pm SD, $* \mathrm{P}<0.05$.

Figure 4

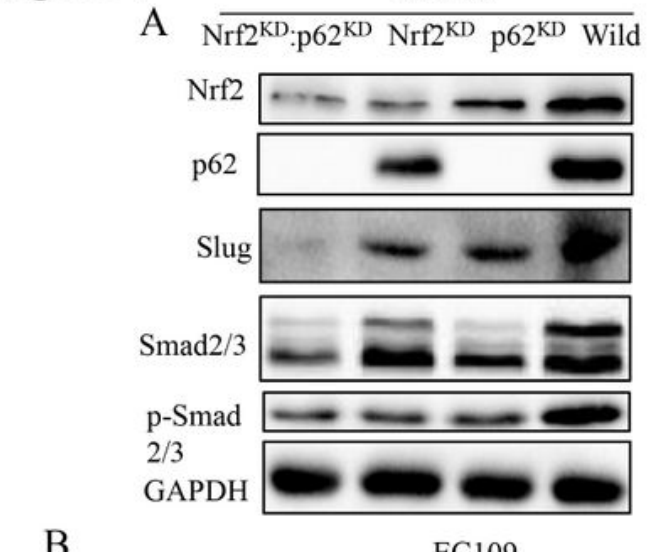

EC109
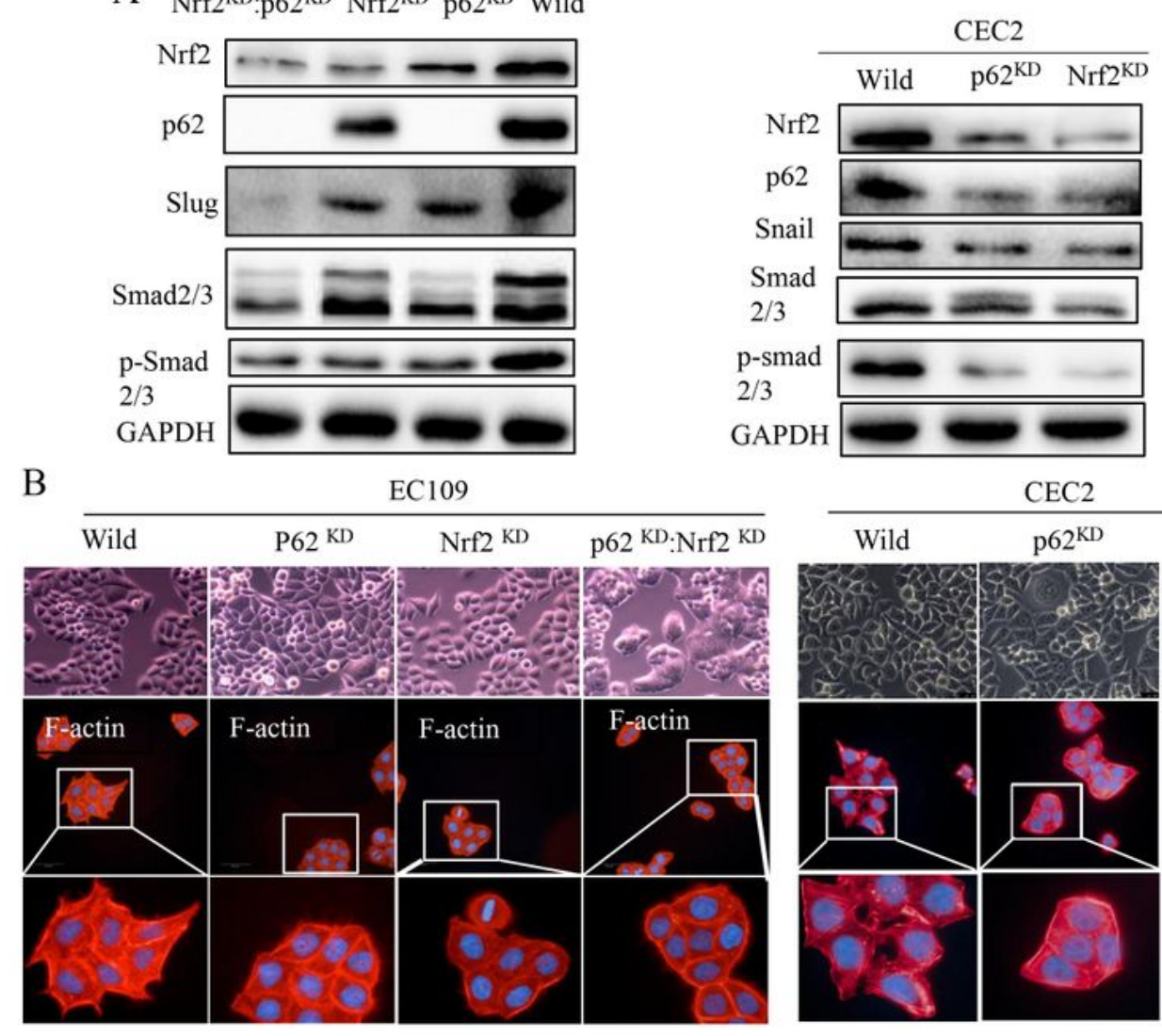

$\mathrm{B}$

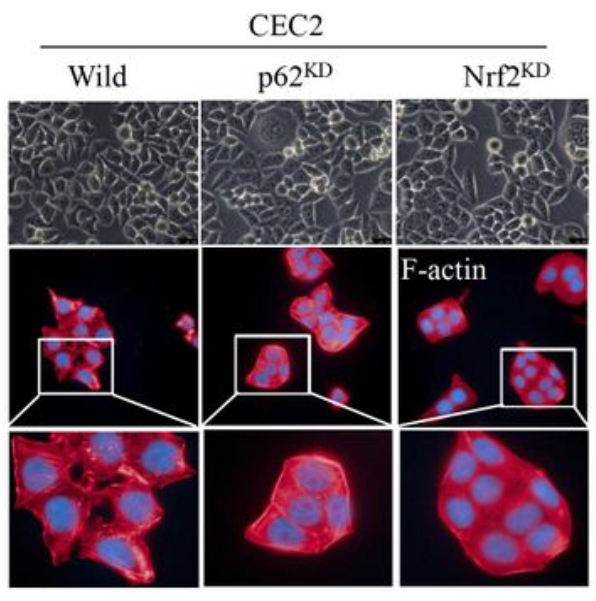

\section{C}
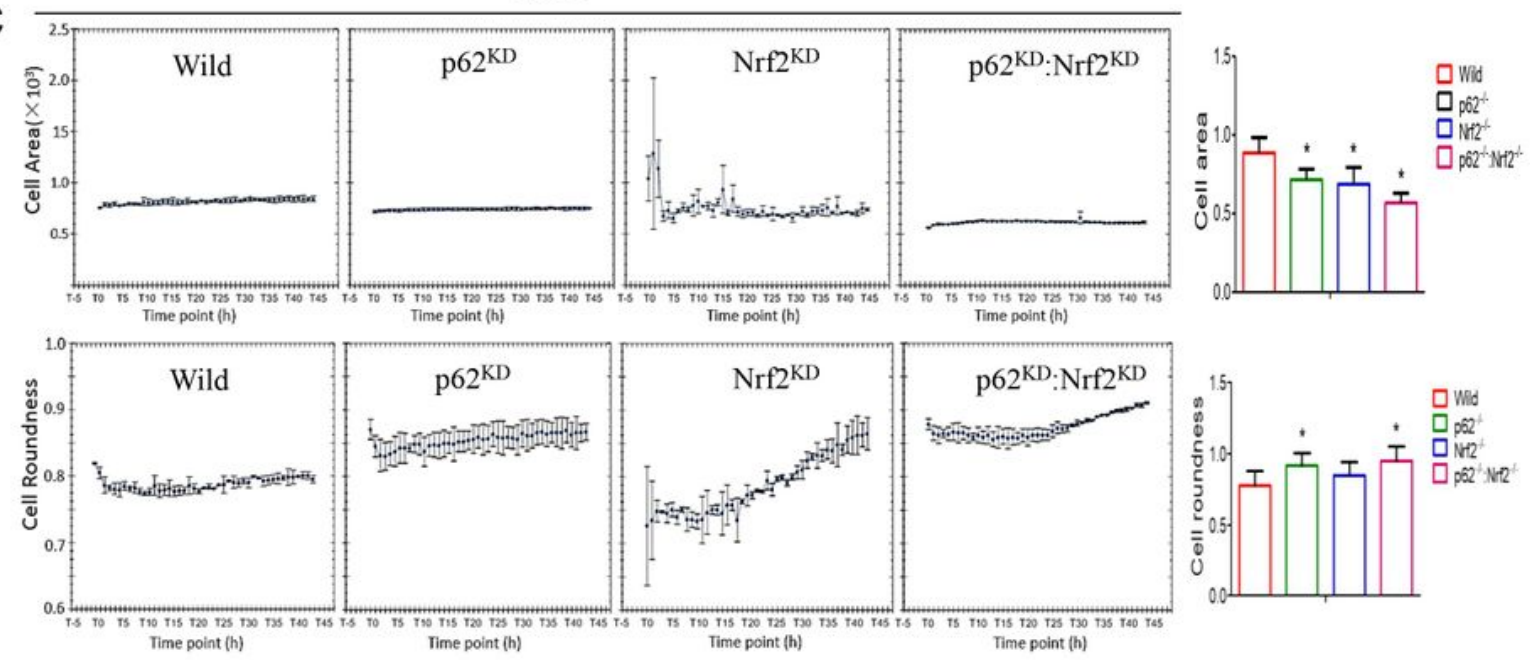


\section{Figure 4}

After knockdown of p62 or Nrf2, EMT and F-actin polarization of ESCC cells were inhibited and autophagy of ESCC cells was promoted. (A) After the knockdown of p62 or Nrf2 in EC109 and CEC2 cells, wild cells were used as a control, and western blot detected the expression levels of p62 or Nrf2 and EMTrelated indicators, and GAPDH was used as a loading control. After knockdown of p62 or Nrf2, the expression of EMT-related indicators in ESCC cells were changed. (B) Cell morphology of ESCC in different treatment groups under an inverted microscope (400x). Rhodamine phalloidin staining was used to determine the distribution of F-actin (red) in ESCC cells of different treatment groups, and the nuclei were stained with DAPI (blue). the expression and polarity distribution of F-actin in Nrf2KD or p62KD:Nrf2KD cells were decreased (C) High-content analysis showed that the cell edges were blurred, and the skeletal areas were significantly reduced. Data are shown as mean $\pm S D,{ }^{*} P<0.05$. 

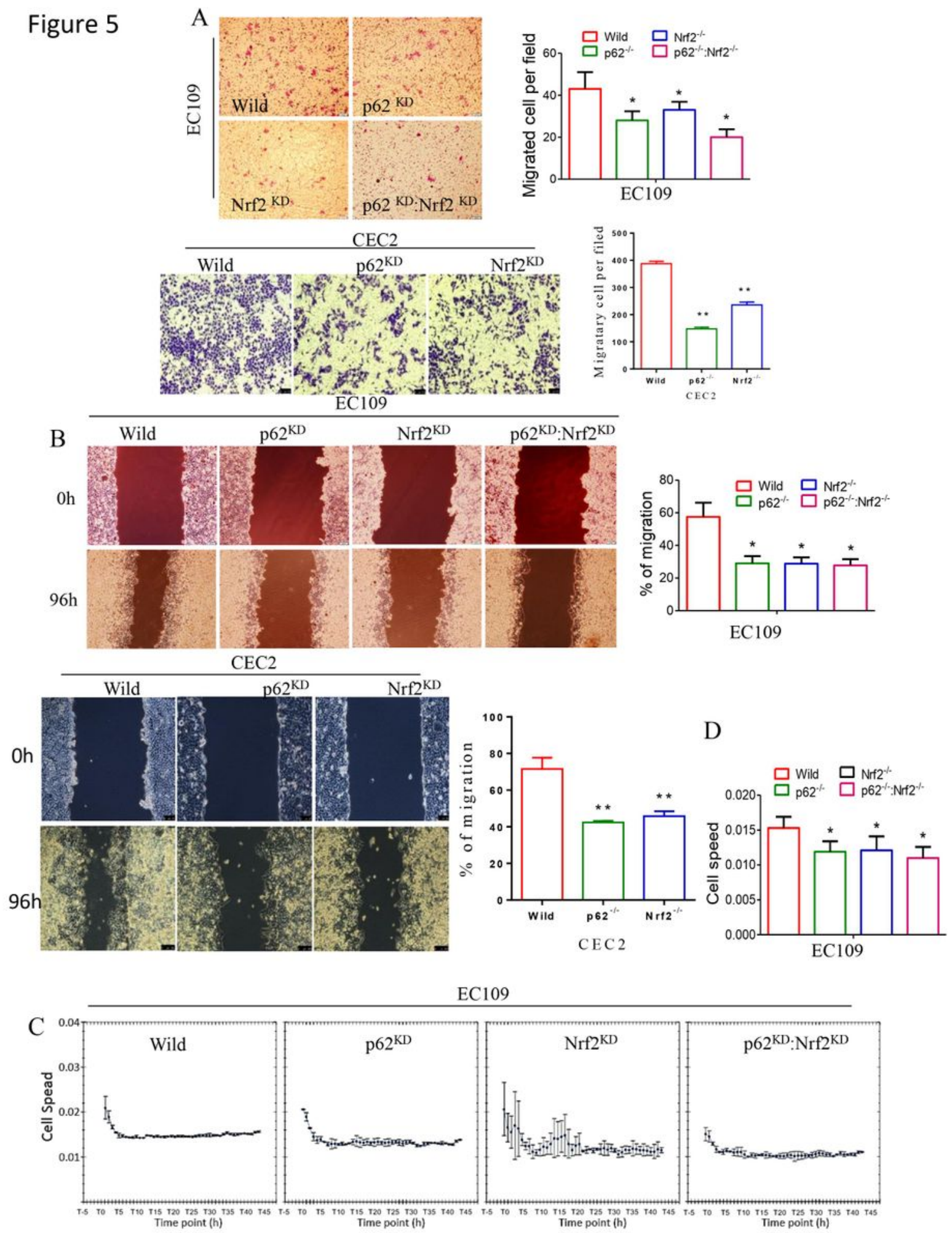

\section{Figure 5}

Inhibiting Nrf2 can damage the migration and invasion ability of ESCC cells in vitro. (A) The invasion of ESCC cells was measured by transwell invasion assays. (B) The migration of ESCC cells was measured by wound healing assays. (C, D) High - cotent analysis showed that 062 or Nrf2 gene knockdown inhibited the migration of EC109 cells. Data are shown as mean $\pm S D$, $* P<0.05,{ }^{*} P<0.01$. 
Figure 6
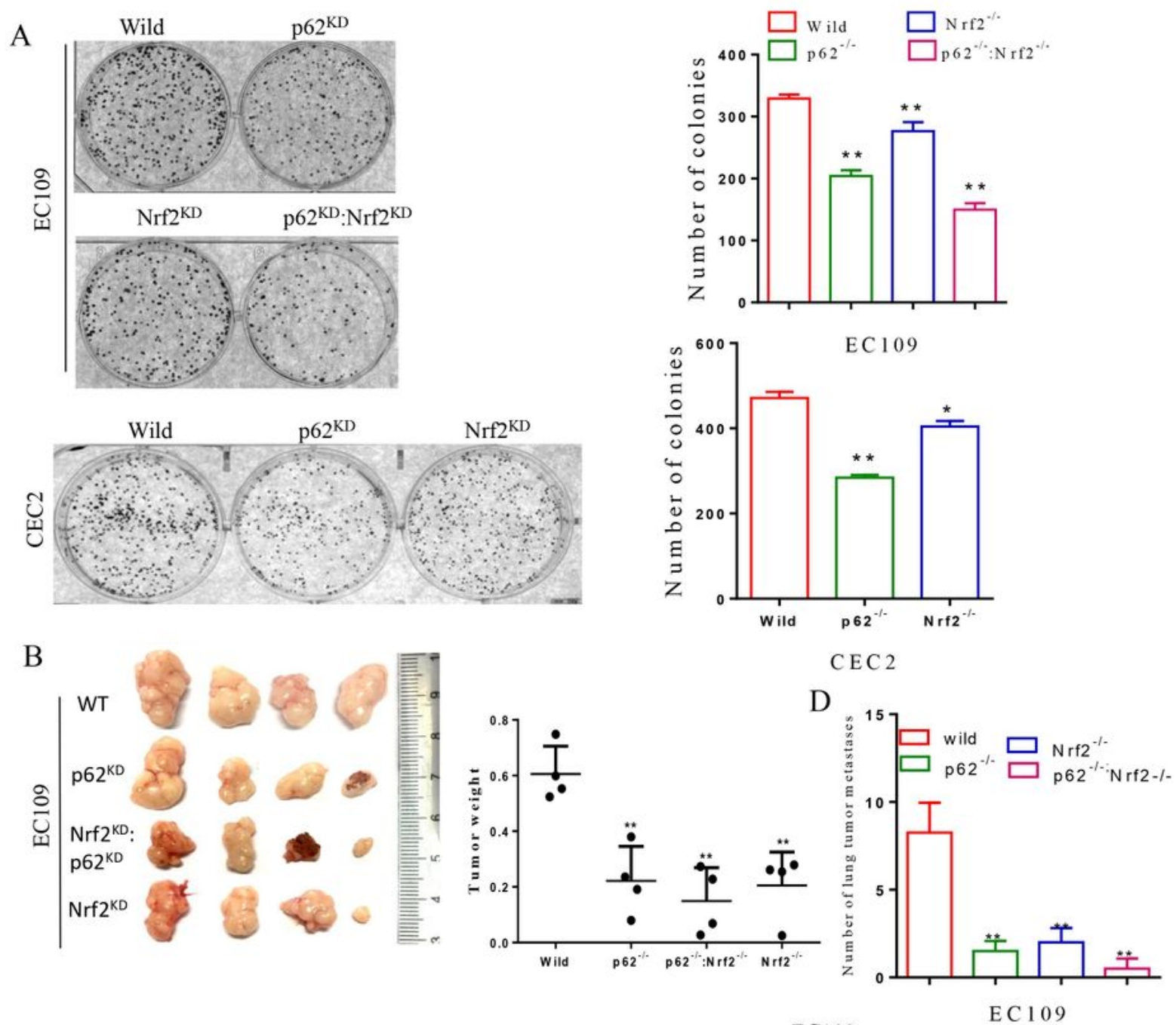

CEC 2

C

$\mathrm{E}$

EC109

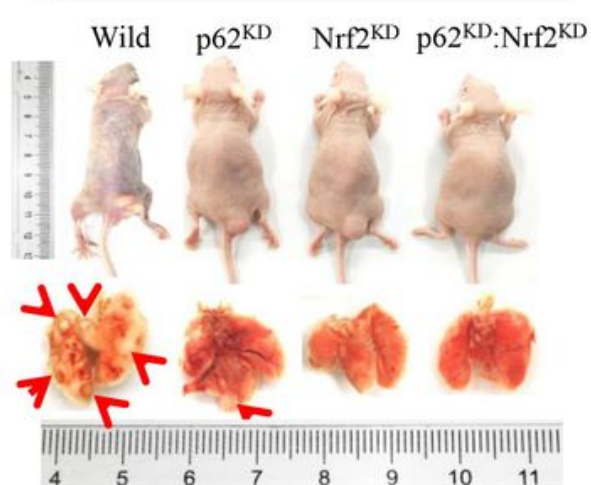

EC109

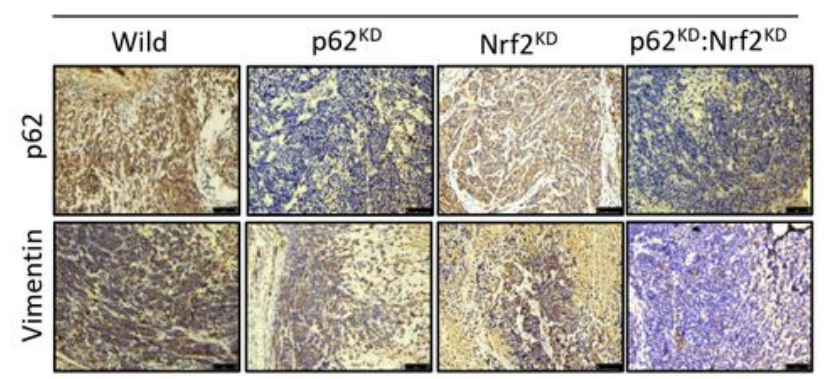

\section{Figure 6}

The knockdown of p62 or Nrf2 inhibits the growth of ESCC cells both in vitro and in vivo. (A) After knockdown p62 or Nrf2 ESCC cells colony formation in vitro. Count the colonies on day 14. Data are means \pm S.D of triplicate cultures from a representative experiment. The knockdown of p62 or Nrf2 inhibits the growth of ESCC cells in vitro. (B) Wild, p62KD, Nrf2KD, and p62KD:Nrf2KD EC109 cells were transplanted into nude mice $(n=4)$ and the tumor was dissected 4 weeks later. The weights of tumors are 
presented as the mean \pm S.D $\left({ }^{\star} P<0.05\right)$. The knockdown of p62 or Nrf2 inhibits the growth of ESCC cells in vivo. (C) Wild, p62KD, Nrf2KD, and p62KD:Nrf2KD EC109 cells were injected into nude mice through the caudal vein injecting $(n=4)$, and lung tissue was removed 8 weeks later. The lung was fixed with $10 \%$ formaldehyde, and the red arrow indicated metastatic nodules. (D) The knockdown of p62 or Nrf2 reduced the lung metastasis capacity of EC109 cells. (E) Immunohistochemical analysis of p62 and Vimentin levels in tumor tissue samples (100x). The knockdown of p62 or Nrf2 decreased Vimentin expression in the tumor. Data are shown as mean $\pm S D, * P<0.05, * * P<0.01$.

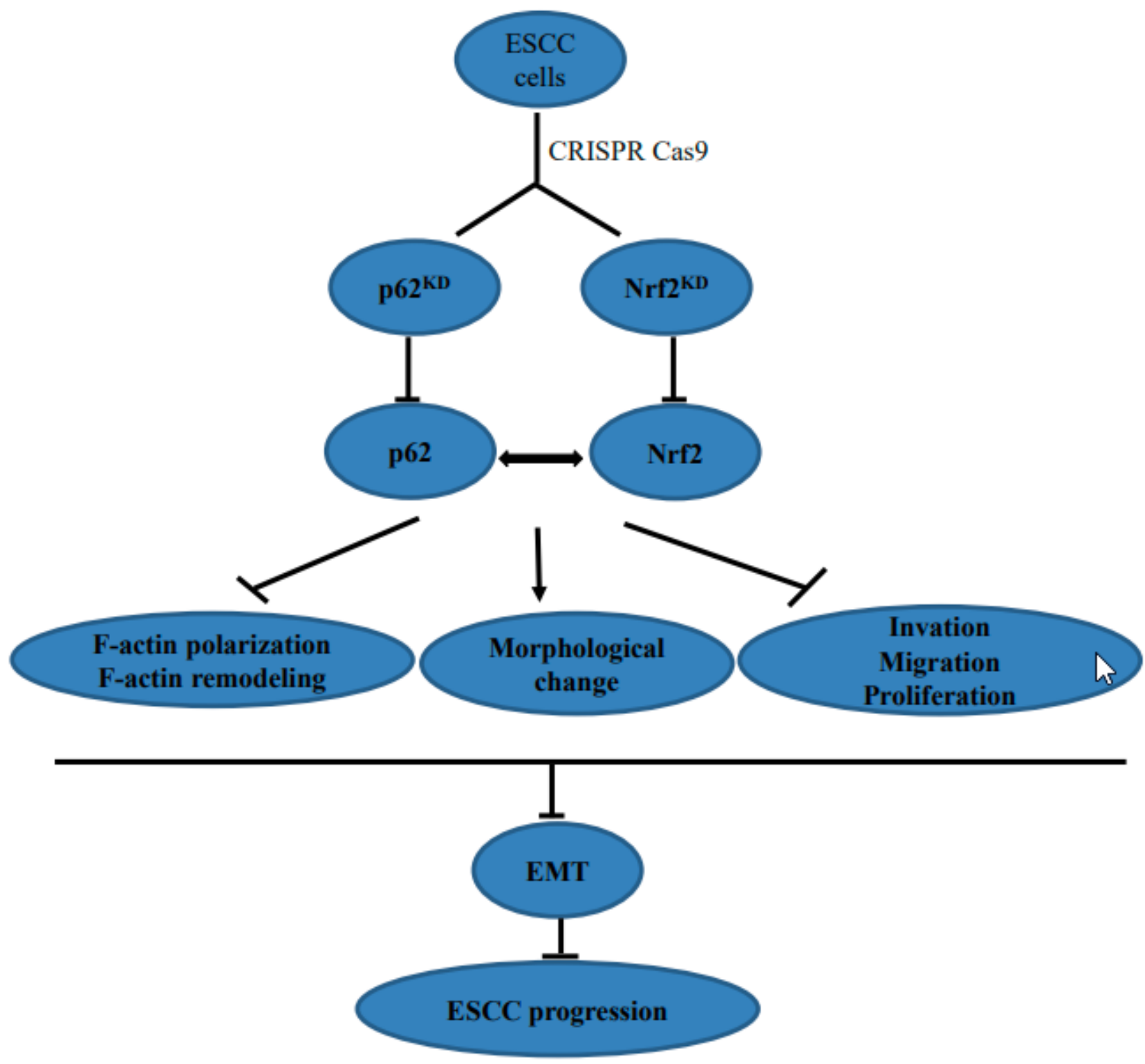

Figure 7

Inhibition of P62 or NRF2 impaired metastasis of esophageal squamous cell carcinoma.

\section{Supplementary Files}

This is a list of supplementary files associated with this preprint. Click to download. 
- figureS1.pdf

- Figure2A.zip

- Figure3A3B.zip

- Figure4A.zip

- supplements120211012.docx 